\title{
Quantifying Pilot Contribution to Flight Safety during Drive Shaft Failure
}

\author{
Lynda J. Kramer \\ Crew Systems and Aviation Operations \\ Branch \\ NASA Langley Research Center \\ Hampton, VA, USA \\ lynda.j.kramer@nasa.gov
}

\author{
Timothy J. Etherington \\ Advanced Technology Center \\ Rockwell Collins \\ Cedar Rapids, IA, USA \\ timothy.j.etherington@nasa.gov
}

\author{
Mary Carolyn Last \\ Crew Systems and Aviation Operations \\ Branch \\ Analytical Mechanics Associates, Inc. \\ Hampton, VA, USA \\ mary.c.last@nasa.gov
}

\author{
Randall E. Bailey \\ Crew Systems and Aviation \\ Operations Branch \\ NASA Langley Research Center \\ Hampton, VA, USA \\ randall.e.bailey@ nasa.gov
}

\author{
Kellie D. Kennedy \\ Crew Systems and Aviation \\ Operations Branch \\ NASA Langley Research Center \\ Hampton, VA, USA \\ kellie.d.kennedy@nasa.gov
}

\begin{abstract}
Accident statistics cite the flight crew as a causal factor in over $60 \%$ of large transport aircraft fatal accidents. Yet, a well-trained and well-qualified pilot is acknowledged as the critical center point of aircraft systems safety and an integral safety component of the entire commercial aviation system. The latter statement, while generally accepted, cannot be verified because little or no quantitative data exists on how and how many accidents/incidents are averted by crew actions. A joint NASA/FAA high-fidelity motion-base simulation experiment specifically addressed this void by collecting data to quantify the human (pilot) contribution to safety-of-flight and the methods they use in today's National Airspace System. A human-in-theloop test was conducted using the FAA's Oklahoma City Flight Simulation Branch Level D-certified B-737-800 simulator to evaluate the pilot's contribution to safety-of-flight during routine air carrier flight operations and in response to aircraft system failures. These data are fundamental to and critical for the design and development of future increasingly autonomous systems that can better support the human in the cockpit. Eighteen U.S. airline crews flew various normal and non-normal procedures over a two-day period and their actions were recorded in response to failures. To quantify the human's contribution to safety of flight, crew complement was used as the experiment independent variable in a between-subjects design. Pilot actions and performance during single pilot and reduced crew operations were measured for comparison against the normal two-crew complement during normal and non-normal situations. This paper details the crew's actions, including decision-making, and responses while dealing with a drive shaft failure - one of 6 non-normal events that were simulated in this experiment.
\end{abstract}

Keywords-flight crew error, aviation safety, increasingly autonomous systems, automation, automation surprise, crew complement, reduced crew operations, single pilot operations, drive shaft failure

\section{INTRODUCTION}

Accident statistics cite the flight crew as a causal factor in over $60 \%$ of large transport aircraft fatal accidents [1]. Yet, the Air Line Pilots Association says that "a well-trained and wellqualified pilot is acknowledged as the critical center point of aircraft systems safety and an integral safety component of the entire commercial aviation system" [2]. The latter statement, while generally accepted, cannot be verified because little or no quantitative data exists on how and how many accidents/incidents are averted by crew actions. Anecdotal evidence suggests crews handle routine failures on a daily basis and Aviation Safety Action Program (ASAP) data [3, 4] supports this assertion but its data are not publicly releasable. Without hard data, the contribution and methods employed by pilots to improve the safety of flight is difficult to define. Developing ways to augment and/or improve a pilot's ability to contribute to flight safety is similarly ill-defined and is hard to characterize in the absence of quantifiable data.

A joint NASA/FAA high-fidelity motion-base simulation experiment specifically addressed this void by collecting data to quantify the human (pilot) contribution to safety-of-flight and the methods used by pilots in today's National Air-space System as they handled normal and non-normal conditions during typical revenue-like flight operations. The off-nominal conditions represented aircraft system failures that can and have occurred during revenue flight operations. These data are fundamental to and critical for the design and development of future increasingly autonomous systems that can better support the human in the cockpit. Different crew complement configurations were tested to gain understanding of the safety afforded by having two crew-members on the flight deck.

This paper details the results and analysis of one of six nonnormal events tested - a generator drive shaft failure. 


\section{METHODOLOGY}

Crew complement (single pilot and crewed configurations) was experimentally manipulated during normal and increasingly challenging non-normal airline operations to quantify the pilot contribution to flight safety.

\section{A. Experiment Design}

The test objectives of the experiment were as follows:

- Establish "baseline" levels of performance and safety with nominal two-crew configuration as well as collect data to assess the performance and safety decrements in reduced crew and single pilot crew complements for present-day flight deck design and certification; and,

- Identify technology requirements from these data for increasingly autonomous systems that might assist future two-crew operations and eventually, enable reduced crew or ultimately, single pilot operations.

To assess human performance and safety, the experiment contrasted two-crew operations to conditions when one of the pilots was absent from the flight deck. The three crew complement configurations were: Two-Crew, Reduced Crew Operations (RCO), and Single Pilot Operations (SPO). If the condition included a temporary absence, it was designated as RCO. If the condition included a permanent absence, it was designated as SPO.

The independent variables were crew complement and scenario. Each crew flew two normal scenarios and six nonnormal scenarios over the two days of data collection. The nonnormal scenarios were grouped into three categories (A, B, and $\mathrm{C}$ ), with two non-normal runs in each category. Category A featured failures, initially unannunciated, with autopilot still available following the failure; Category $\mathrm{B}$ featured annunciated failures with the autopilot still available; and, Category $\mathrm{C}$ featured annunciated failures with autopilot not being available after the failure. Alert type and autopilot state were used to identify workload and automation issues (i.e., by availability of autopilot) and flight crew awareness and monitoring for normal / non-normal operations (i.e., alerting). All flights were flown to landing.

Failures were triggered near top of climb or top of descent. This paper details one Category B failure - a generator drive shaft failure. Etherington et al [5] provides a detailed description of the experiment design (factors, metrics, and run matrix) and details one Category $\mathrm{C}$ failure. The Auxiliary Power Unit (APU) was inoperative to increase workload for all scenarios and the APU was listed as INOP in the flight release and appropriately tagged in the flight deck.

The data shown here is taken from 18 nominal Two-Crew runs and 18 drive shaft failure non-normal runs (6 SPO, 6 $\mathrm{RCO}, 6$ Two-Crew). For the RCO configuration, the nonnormal started out with First Officer flying from the right seat and the Captain resting in the left seat, isolated in sight and sound from the cockpit. Two minutes after the flying pilot was alerted to the drive shaft failure, the resting pilot returned to flying duties in the cockpit. For the SPO configuration, each pilot flew from the left seat.

\section{B. Participants}

Thirty-six pilots (18 crews total), representing 5 airlines, participated in this experiment. Each pilot held an Airline Transport Pilot rating and was current in the 737-800 aircraft as either Captain or First Officer. All participants were male. Crews were paired by function (Captain or First Officer) and employer to minimize conflicts in training, standard operating procedures, and crew resource management techniques. Crews were instructed to bring their company's paper and/or electronic charts and 737-800 checklists with them to further reduce conflicts in training and standard operating procedures.

\section{Simulator}

The research was conducted using the B-737-800 simulator operated by the FAA AFS-440 at Oklahoma City, OK. The simulator is Level D-certified and can be used for both initial and recurrent training. The simulator, although a Level D training device, is also fitted with experimental controls, modifications, and recording capability to support AFS-440's research mission. The fidelity of the simulator and the recording capability were both critical to this research effort.

The test was set up to replicate a normal airline operation in today's National Airspace System. An air carrier flight from Denver (KDEN) to Albuquerque (KABQ) was simulated. Dispatch paperwork for the flight was provided to the crews and constituted the flight release.

The simulated weather en-route contained significant areas of convective activity along the Rocky Mountain front range and strong Northerly winds that required a north departure out of KDEN before a circuitous route to the west and then south to KABQ. This same planned route of flight was used for the entire two days of data collection. Weather and visibility were designed to affect any diversion decisions [5].

A live controller and pseudo-pilot(s) were tied into the simulation radio in real-time to simulate Air Traffic Control (ATC) and some proximate traffic to promote realism and maintain realistic pilot workload levels. A confederate also served as dispatcher in the Airline Operations Center and provided communications as necessary and appropriate when contacted.

\section{Training}

No additional training was conducted for the crews as they were qualified and current B737-800 pilots and the simulator was Level D-certified.

The crews were briefed on the purpose of the experiment and received the dispatch paperwork. The crews were instructed to use their company's standard operating procedures and checklists for the entire test, including any company dispatch calls and cabin crew communications as they would on any revenue flight.

Prior to boarding the aircraft, the crew reviewed the paperwork and discussed the flight plan and flight conduct. Once they boarded the aircraft, the crew did a familiarization check and reviewed the simulator safety briefing. Known simulator-isms and aircraft differences were identified and discussed with the crew prior to run initiation.

NASA Langley Research Center 
The aircraft initial condition for the nominal run was in the hold-short of Runway 35L at KDEN with the engines running, parking brake set and aircraft configured for takeoff. The Flight Management System (FMS) was pre-loaded with the planned flight routing and the crews were asked to double check the entries. After review and confirmation of the cockpit switches/set-up and completion of their normal checklists, the crew called KDEN tower for departure.

Following clearance from ATC, the crew flew an entire nominal flight from KDEN to KABQ following the planned route of flight. The nominal flight served as a baseline for 'normal' airline two-crew operations (i.e., nominal data) to which the non-normal runs flown in the RCO and SPO configurations would be compared. The nominal flight also promoted familiarity for the two-person crew interaction during the approximately 1.3 hours of flight time required for completion. This nominal flight was always flown as the first run on Day 1 of data collection for each crew.

\section{RESULTS}

The results shown here describe the major findings of only one of the Category B failure conditions, a Generator Drive Shaft failure.

The Boeing 737 is a low-wing passenger aircraft powered by two CFM56-3C1 turbofan engines. Its electrical power system is made up of three main systems: the alternating current (AC) power system, the direct current (DC) power system, and the standby power system. Primary electrical power is supplied by two engine integrated drive generators (IDGs) supplying three-phase 115 volt, $400 \mathrm{~Hz}$ cycle AC. Each IDG normally supplies its own bus system but it can also supply power to the transfer bus of the opposite side automatically via the Bus Transfer Relay if one IDG fails. The APU drives a generator that can supply power to one Main AC Bus and both Transfer Buses in flight. (The APU was inoperative in this test however.) The DC system consists of three major buses: DC Bus 1, DC Bus 2, and the Battery Bus. DC Bus 1 and DC Bus 2 are powered directly by two Transformer Rectifier (TR) units that operate in parallel, each receiving $\mathrm{AC}$ inputs power from its respective $115 \mathrm{~V}$ AC Transfer Bus. These two buses are backed up by a third, identical TR (TR-3) through an isolation diode. In addition to its back up function, TR-3 is the primary source of power for the Battery Bus. As long as power is available to TR-3, it will power the Battery Bus. If power is lost to TR-3, the Battery Bus will automatically transfer to receive power from the Hot Battery Bus. The aircraft is air-conditioned and pressurized using ambient external air and hot air generated from the engine compressors. The system operates automatically to maintain the settings and demands required of it using electromechanical devices.

Electrical failures are complex and difficult to understand. There are cascading failures where multiple systems fail in parallel or in sequence. They can even seem random at times, so pilots either don't make the connection to the electric system or they don't connect all the failures lights to the single electrical system. In addition, load shedding, where smart systems manage the overall electrical load, adds to the complexity and difficulty diagnosing the electrical failure. Load shedding is not communicated to the pilot, is not typically taught in systems training because of complexity, and operates differently each time because it is dynamic and depends on actual electrical loads. One example of a system that is affected intermittently with load shedding is the pressurization system.

Pressurization is maintained by controlling an outflow valve while the air conditioning system supplies positive pressure air. With the valve open, the airplane will not pressurize. With the valve closed, the cabin pressure will start to rise. The valve is normally automatically opened and closed to maintain a scheduled cabin pressure. To maintain pressurization, at least one pack - air cycle machines that are driven by engine bleed air - must remain on. The packs depend on electrical power for operation. If both packs trip off, even with the outflow valve closed, the cabin will slowly lose pressure. The valves are electrically controlled and pneumatically operated.

With electrical problems, the packs will trip at random times due to fan cooling being intermittently load shed. If the pack cannot maintain the selected temperature, the pack will trip off. To keep the pressurization working, continuous monitoring and resetting of the packs during electrical failures may be necessary. The AUTO FAIL light may come on as well. The procedure for resetting a pack comes from the PACK light. If the pilot follows the AUTO FAIL light procedure, it does not direct them to reset the pack but only to eventually get the pressurization panel into manual mode and close the outflow valve. This does not restore pressurization (the outflow valve is already closed) and cabin altitude will increase above acceptable limits. The cabin depressurization warning horn will sound when the cabin exceeds $10,000 \mathrm{ft}$.

The generator drive shaft failure was modeled as a left-side shaft shear with the right-side unable to pick up the electrical load. The APU was inoperative. The drive shaft failure was initially annunciated to the flight crew through illumination of the: a) DRIVE light on the overhead standby power panel and TRANSFER BUS OFF and SOURCE OFF lights on the overhead bus transfer panel; and, b) left and right side MASTER CAUTION lights and HYD and OVERHEAD system annunciator lights on the glare shield annunciation panel. Additionally, if the A-side autopilot was engaged, it automatically disconnected and the autopilot disconnect horn sounded. The B-side autopilot was still available after the failure. Loss of AC Bus 1 caused the yaw damper, probe heat, and left hand side pack to switch off; multiple overhead lights to illuminate such as the LOW PRESSURE lights on electrical 1 and on the fuel pumps. As the flight progressed, the dynamic load shedding of the remaining AC Bus affected other systems such as the right pack.

\section{A. Failure Handling and Flight Path Control}

The drive shaft failure occurred at waypoint DATME approximately 15 minutes prior to the top of descent during the cruise phase of flight at $36,000 \mathrm{ft}$ mean sea level (MSL) while heading south toward $\mathrm{KABQ}$. 
Once the failure occurred, 15 out of 18 pilots/crews declared an emergency with ATC. All SPO pilots declared an emergency. The three crews ( 2 RCO, 1 Two-Crew) who did not contact ATC and declare an emergency did not discuss with each other if they should declare an emergency or not. The pilots in the Two-Crew configuration did contact ATC and let them know they had an electrical failure and requested the KABQ Runway (Rwy) 08 ILS approach instead of the RNAV (RNP) RWY 08 approach.

The flight was planned for the RNAV arrival to KABQ Runway 8. Following the failures, RNAV approach procedures are not authorized since two sources of $\mathrm{AC}$ power are required for this operation. Eleven crews requested vectors from ATC for the KABQ Rwy 08 ILS approach. The remaining crews (2 Two-Crew, 3 RCO, 2 SPO) flew the RNAV arrival as planned. Crew complement does not appear to have influenced the decision to continue flying the RNAV approach after the drive shaft failure event as there was nearly an equal distribution between the three configurations for these crews.

Seven of the 18 pilots/crews experienced a cabin depressurization event while completing the approach with the drive shaft failure as they didn't continuously monitor and reset the packs tripped off by load shedding. Interestingly, only 2 crews ( 1 Two-Crew, 1 RCO) of the 7 donned oxygen masks during this depressurization event even though it is required pilot equipment above $10,000 \mathrm{ft}$ MSL. $50 \%$ of the SPO runs had a depressurization event and none of the single pilots donned an oxygen mask. The initial altitude at which the depressurization warning sounded and the duration time to descend to $10,000 \mathrm{ft}$ by the 5 crews ( 1 Two-Crew, 1 RCO, and 3 SPO) who did not don oxygen masks ranged from $10,800 \mathrm{ft}$ MSL/29 seconds to $15,420 \mathrm{ft}$ MSL/219 seconds.

\section{B. Checklist Usage}

Time-to-first correct checklist was used as a metric for quick and proper troubleshooting of equipment problems.

For the Drive Shaft failure, it was an alerted failure with annunciation on the flight deck that had a direct entry in the Quick Reference Handbook (QRH) with the DRIVE checklist. Two other indications, TRANSFER BUS OFF and SOURCE $\mathrm{OFF}$, with direct entries in the QRH, were also annunciated on the flight deck. After assessing the myriad of lights illuminated on the overhead panel due to left drive shaft failure and subsequent power shedding, the critical checklist pilots should have executed was the DRIVE checklist which disconnects the drive from the motor to prevent further damage to the generator and potentially an engine fire.

Table 1 reveals that $50 \%$ of the pilots in the Two-Crew configuration properly identified the failure and chose the DRIVE checklist as their first one to execute, while only $17 \%$ of the pilots in either the RCO or SPO configurations initially chose the correct DRIVE checklist. One SPO pilot found that maintaining flightpath control, communicating with ATC, and dealing with the electrical failures was so demanding that he did not run any checklists. Five crews ran more checklists than the initial one as they troubleshot the electrical failures. Taking that into consideration, $67 \%$ of the Two-Crew, $33 \%$ of the $\mathrm{RCO}$, and $33 \%$ of the SPO crew configurations ran the correct
DRIVE checklist prior to landing. The remaining pilots/crews used only the SOURCE OFF checklist and/or TRANSFER BUS OFF checklist to attend to the drive shaft failure (Table $1)$.

Crew complement was statistically significant $(\mathrm{F}(2,14)=3.78, \mathrm{p}=0.049)$ for time-to-start initial electrical checklist, but not operationally relevant. On average, the TwoCrew and SPO crews took approximately 100 seconds to start the first electrical checklist and RCO crews took approximately 241 seconds. All but one of the RCO crews delayed checklist usage until the resting pilot was re-engaged. Accounting for the two minute fixed delay for the RCO crews, the time to start the initial checklist was around 20 seconds later for the RCO compared to the Two-Crew and SPO crews. This delay is incurred due to the flying pilot who briefed the returning pilot on the current situation of their aircraft upon his return from crew rest.

TABLE I. ELECTRIAL CHECKLISTS ACCOMPLISHD BY CREW TYPE

\begin{tabular}{|l|l|c|c|c|c|c|}
\hline \multirow{2}{*}{ Crew } & \multicolumn{3}{|c|}{ Initial Checklist } & \multicolumn{3}{c|}{$\begin{array}{c}\text { Electrical-Related } \\
\text { Checklists Completed }\end{array}$} \\
\cline { 2 - 7 } & $\begin{array}{l}\text { Checklist } \\
\text { Name }\end{array}$ & $\begin{array}{c}\text { Start } \\
\text { (sec) }\end{array}$ & $\begin{array}{c}\text { Total } \\
\text { (sec) }\end{array}$ & Drive & $\begin{array}{c}\text { Source } \\
\text { Off }\end{array}$ & $\begin{array}{c}\text { Transfer } \\
\text { Bus Off }\end{array}$ \\
\hline RCO & Source Off & 98 & 24 & & X & \\
\hline RCO & $\begin{array}{l}\text { Transfer } \\
\text { Bus Off }\end{array}$ & 235 & 69 & & & $\mathrm{x}$ \\
\hline RCO & Source Off & 122 & 36 & & $\mathrm{X}$ & \\
\hline RCO & Drive & 224 & 36 & $\mathrm{x}$ & & \\
\hline RCO & $\begin{array}{l}\text { Transfer } \\
\text { Bus Off }\end{array}$ & 253 & 29 & $\mathrm{x}$ & & $\mathrm{x}$ \\
\hline RCO & $\begin{array}{l}\text { Transfer } \\
\text { Bus Off }\end{array}$ & 516 & 27 & & & $\mathrm{x}$ \\
\hline SPO & ----------- & -- & -- & & & \\
\hline SPO & Source Off & 131 & 82 & & $\mathrm{x}$ & \\
\hline SPO & Source Off & 46 & 30 & $\mathrm{x}$ & $\mathrm{x}$ & $\mathrm{x}$ \\
\hline SPO & Drive & 98 & 32 & $\mathrm{x}$ & & \\
\hline SPO & Source Off & 64 & 28 & & $\mathrm{x}$ & \\
\hline SPO & Source Off & 162 & 84 & & $\mathrm{x}$ & \\
\hline Two & Source Off & 226 & 28 & & $\mathrm{x}$ & \\
\hline Two & Drive & 67 & 45 & $\mathrm{x}$ & & $\mathrm{x}$ \\
\hline Two & Drive & 120 & 41 & $\mathrm{x}$ & & \\
\hline Two & $\begin{array}{l}\text { Transfer } \\
\text { Bus Off }\end{array}$ & 77 & 48 & $\mathrm{x}$ & & $\mathrm{x}$ \\
\hline Two & Drive & 41 & 31 & $\mathrm{x}$ & & \\
\hline Two & $\begin{array}{l}\text { Transfer } \\
\text { Bus Off }\end{array}$ & 79 & 65 & & & \\
\hline
\end{tabular}

Time-to-complete the initial checklist was considered another indicator for safely handling failures. Crew complement was not significant $(\mathrm{F}(2,14)=0.70, \mathrm{p}=0.513)$ for time-to-complete the initial electrical checklist. The overall mean time for the crews to complete the checklist was 44 seconds. The three checklists for this electrical failure were short and straightforward since the APU was inoperative. All ended with the instruction 'plan to land at the nearest suitable airport' and with the note 'only one main AC power source remains'.

No checklist items in the DRIVE, TRANSFER BUS Off, or SOURCE OFF checklists were missed as the pilots initially handled the drive shaft failure. However, as load shedding 
occurred, 7 of the 18 pilot/crews experienced a cabin depressurization event by not properly managing the pack systems.

\section{Diversion Decision}

The test was staged to evaluate decision-making by the flight crew. A diversion decision after a failure was part of this decision-making test which tasked the pilots to consider distance to fly with the failure, the weather at each airport (KABQ and possible divert airports), and the time it took to troubleshoot the problem. Another factor that played specifically in the pilot's decision-making process for a left drive shaft failure was that they had only one source of $\mathrm{AC}$ power remaining since the APU was inoperative.

The reality is that when the drive shaft failure happened within 15 minutes to the top of descent, the best option was to continue a landing to the destination at KABQ. For the drive shaft failure, all crews, regardless of crew configuration, continued to the destination and landed safely. Santa Fe was the alternate airport for the flight but even though it was in the direct flight path, it had the same weather as Albuquerque (1000 foot ceiling and 3 miles visibility), a shorter runway, and would require a steeper descent rate or ATC vectoring on a flight path that would be the same distance as going to the destination. Since Albuquerque, the destination airport, was only an additional 60 miles with better support facilities and the Flight Management System was already configured for flight to KABQ, Santa Fe was not considered a better alternative by any crews for the drive shaft failure runs.

\section{Workload}

The NASA Task Load Index (TLX) captured a subjective rating (0 [Low] to $100[$ High]) of perceived task load. There are six subscales of workload represented in the NASA TLX: mental demand, physical demand, temporal demand, performance, effort, and frustration level [6]. The overall score results of this measure were examined to investigate task load variation.

Not surprisingly, independent analyses revealed significant differences between the nominal and drive shaft failure runs for both pilot-flying $(\mathrm{PF})(\mathrm{F}(1,34)=5.98, \mathrm{p}=0.02)$ and pilotmonitoring $(\mathrm{PM})(\mathrm{F}(1,28)=6.46, \mathrm{p}=0.017)$ TLX ratings (Fig. $1)$. [The boxplots show the median ratings, with the $25^{\text {th }}$ and $75^{\text {th }}$ percentile spread in the data; the maximum and minimum values; and mean ratings (connected by a line).] For the drive shaft failure runs, pilots rated their overall workload as being moderate, as reflected in the PF (mean rating=52) and PM (mean rating $=51$ ) TLX ratings.

There were no significant $(\mathrm{p}>0.05)$ crew complement differences for PF overall TLX ratings or PF subscale TLX ratings during a drive shaft failure run. Single pilot operations were rated as having moderately high workload (mean=67) while crewed operations were rated as having moderate workload (Fig. 2).

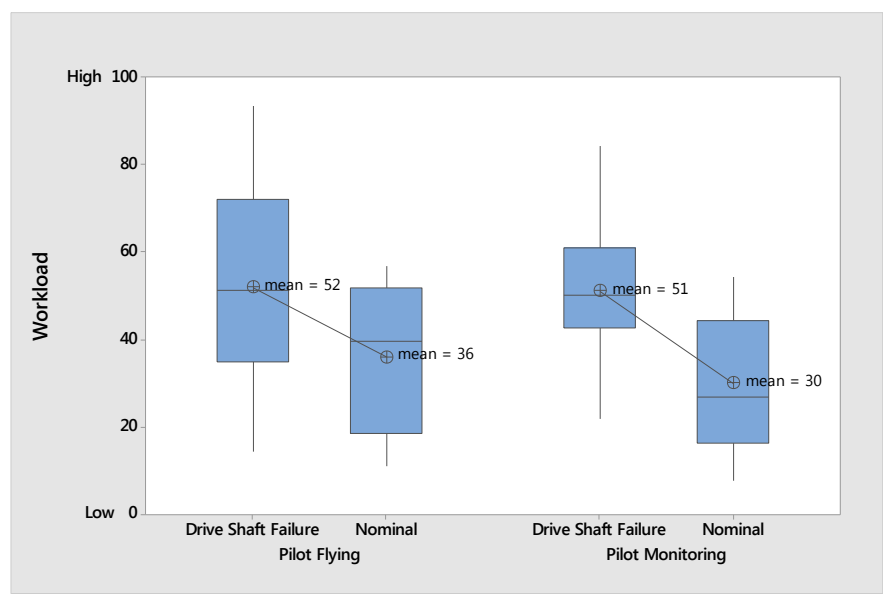

Fig. 1. Overall TLX pilot-flying and pilot-monitoring ratings for drive shaft failure and nominal runs

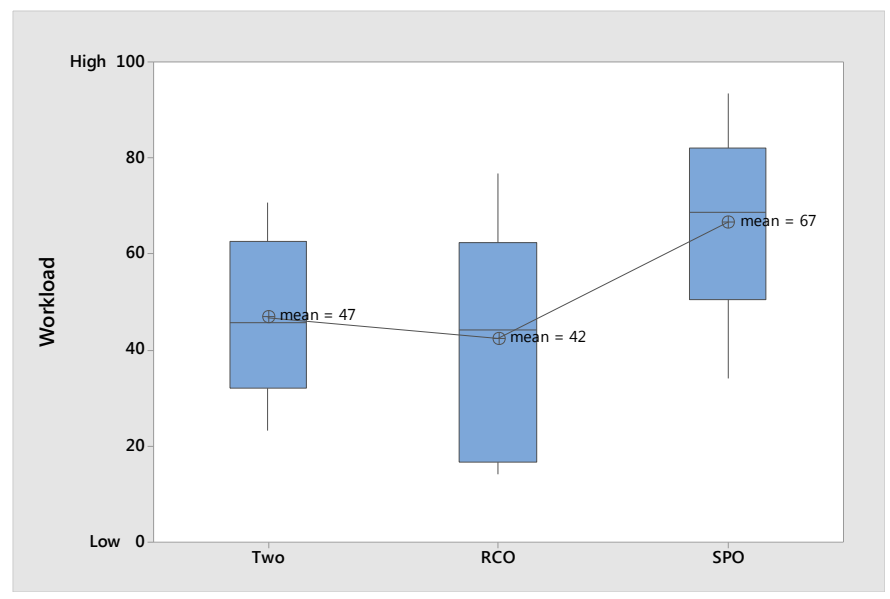

Fig. 2. Overall TLX ratings for pilot-flying drive shaft failure runs by crew configuration

Although the differences are not statistically significant, the physical workload TLX rating data highlights the significant change in the physical demands placed on the pilot-flying during Two-Crew and RCO conditions to SPO operations (Fig. 3).

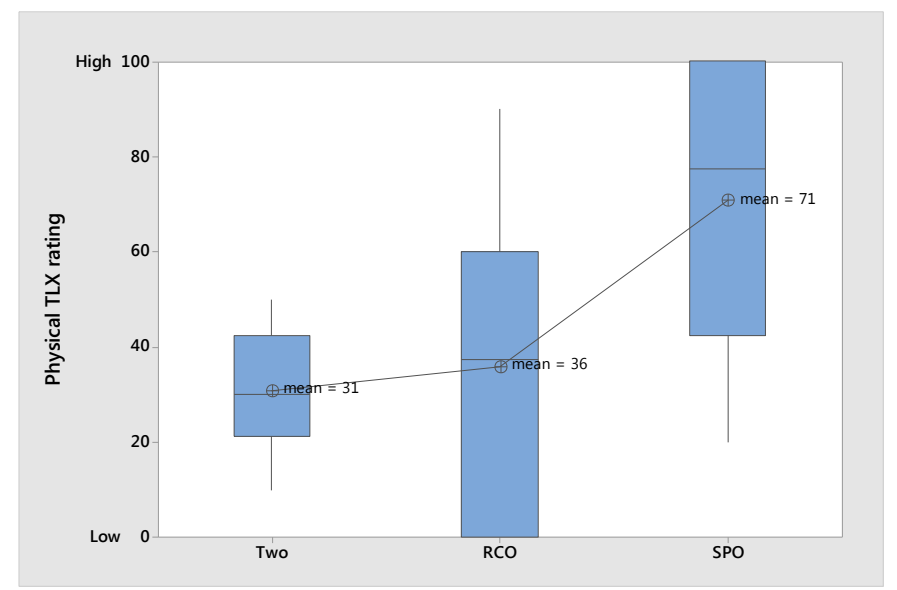

Fig. 3. Physical TLX ratings for pilot-flying drive shaft failure runs by crew configuration 


\section{E. Safety of Flight}

Perceived level of safety was self-assessed using a Likert type scale from 1-7, where 1 was completely acceptable and 7 was completely unacceptable.

An ANOVA revealed significant differences $(\mathrm{F}(1,34)=15.57, \quad \mathrm{p}<0.001)$ between the nominal runs (median=1) and drive shaft failure runs (median=2.5) for PF Perceived Safety of Flight ratings. Fig. 4 illustrates these differences, where from an overall perceived level of safety for the PF compared to normal flight, this failure was difficult for some pilots as indicated by the large spread in data.

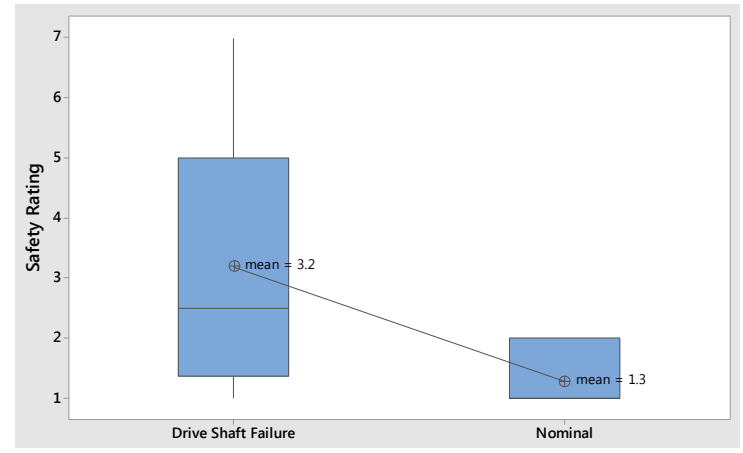

Fig. 4. Perceived safety of flight ratings for pilot-flying drive shaft failure and nominal runs collapsed across crew configuration

An ANOVA showed significant crew complement differences $(\mathrm{F}(2,15)=3.75, \mathrm{p}=0.048)$ for $\mathrm{PF}$ perceived safety of flight ratings. Fig. 5 shows the PF rating for each crew complement configuration. Pilots viewed the safety of this failure as unacceptable during single pilot operations (median rating=4.5) where the pilot had to simultaneously maintain flightpath control, communicate with ATC/Dispatch, and perform checklists. PF ratings indicated safety of flight was acceptable for this failure in the Two-Crew configuration.

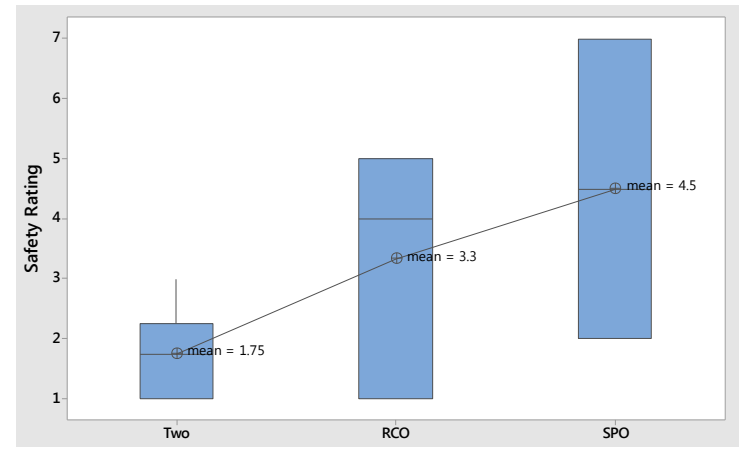

Fig. 5. Perceived safety of flight ratings for pilot-flying drive shaft failure runs by crew configuration

\section{DISCUSSION}

This paper highlights the data and analysis for one nonnormal scenario out of six evaluated, a generator drive shaft failure, and it supports the conclusion that anything less than two crew members will require significant redesign of automation and increased levels of automation support. Safety of flight was compromised when a single pilot had to troubleshoot and attend to the electrical failure with dynamic load shedding while simultaneously maintaining flightpath control and communicating with air traffic control. Workload increased to moderately high levels during single pilot operations. The effects of reduced crew (i.e., the RCO condition) was evident but not as severe as SPO.

When the drive shaft failure occurred, overhead and master caution lights indicated electrical problems on the left side system, the autopilot disconnected, and load shedding to manage the airplane's electric loads began. Troubleshooting and correctly determining the cause of the electrical problem was two times better in the two-crew configuration than in the reduced crew or single pilot configurations. However, even in the two-crew configuration, one-third of the pilots did not accurately identify that a drive shaft failure was responsible for the degraded electrical system and its associated non-normal checklist was the critical one to execute. The current-day caution and warning system clearly identifies a fault but does not articulate or annunciate the root cause nor the systems and capabilities that are impacted, degraded, or inoperative.

Approximately $39 \%$ of the crews had a cabin decompression event during the descent phase of flight as they did not adequately attend to intermittent pack trips caused by dynamic load shedding. Part of this may be a simulation artifact. Some pilots indicated that in the actual airplane they would have felt the pressurization problem developing (ears popping) and would have actively managed the issue. Some pilots were reluctant to resetting the packs more than one time. New 737-800 cockpit applications, such as interactive, electrical and air system synoptic pages and electronic checklists, could be developed to aid the flight crew in identifying critical items that had failed and automatically provide them the associated checklists (prioritized from most critical to least) to attend to the failures.

Not all crews appropriately donned their oxygen masks when the pressurization horn sounded. In some cases, it was workload shedding by the pilots and they felt that they couldn't turn their attention from the immediate problem to don the mask. In others, it was a combination of workload shedding and situation awareness; several times, the crews were already descending and nearing 10,000 ft MSL. Putting on the mask took valuable time to reset their radios and intercom so they could communicate. In debrief commentary, the pilots felt that they would be at or below acceptable altitudes soon enough that hypoxia would not be a concern and masks were of lesser importance than other duties and tasks. Note that descent to $10,000 \mathrm{ft}$ MSL was not always practical since the minimum safe altitude reaches as high as $14,800 \mathrm{ft}$ MSL on the RNAV arrival into $\mathrm{KABQ}$.

This failure occurred about 15 minutes prior to top-ofdescent; diversion to an alternate airport was not a proper course of action. However, once the failure occurs, even though the RNAV arrival was loaded in the FMS, the aircraft was degraded and the RNAV arrival was not an approved operation. Some airlines have specific call-outs in their QRH which identify equipage requirements for certain operational capabilities. These data are not, however, automatically provided. The crew is aware from the caution and alerting system that AC power is degraded, but not that RNAV arrivals 
are not approved in this condition. They must actively seek out and search for the information while simultaneously working the systems, flying and navigating the aircraft, while communicating to ATC and airline dispatch. In many cases, the pilots did not know that RNAV arrivals were not an approved operation and that did not matter. They exercised their good judgement and requested ATC assistance by asking for vectors and a long ILS approach procedure. When in high workload conditions, especially in an SPO configuration, assistance wherever and whenever possible was a good thing, and the less demanding tasks, the better.

For this failure, the workload and performance decrements as crew complement changed may have been optimistic because the failure occurred so near to top of descent. At this point, the aircraft is approaching the planned destination and the route of flight is basically loaded into the FMS. The flight duration was not excessive.

Although the perceived safety of flight data shows that RCO or SPO operations are not desirable, all crews/pilots were able to safety conduct and complete a safe landing. For the SPO case, some task shedding and some errors and procedural omissions were noted although errors and procedural omissions were also noted during Two-Crew and RCO conditions. The TLX physical demand data is indicative of how the change in the crew complement significantly impacts the number of switch actions, button presses, control inputs, and other ancillary duties which are now the burden of a single pilot, thus, significantly increasing the risk of errors on the flight deck.

\section{CONCLUDING REMARKS}

This paper highlights the effect of changing the human pilot contribution - by crew complement changes to RCO or SPO to the level of the safety and performance in today's airspace with today's cockpit design. The data indicate the adaptability of pilots/flight crew to overcome non-normal conditions and complete safe recoveries. The data also indicate that single pilot operations are not acceptable due to the significant task demands and workload to handle the drive shaft generator failure.

Data analysis of the nominal runs and six failure runs is being used to establish quantitative baseline levels of performance and flight safety during nominal two-crew operations. These nominal data are being used to assess performance and safety decrement in reduced crew or single pilot operations using current-day flight deck design and certification. The nominal data are also being employed to identify and develop new applications and technology requirements for increasingly autonomous systems to assist pilots during dynamic and unplanned situations and perhaps future operations with two-crew, reduced crew, or possibly commercial single pilot operations.

\section{ACKNOWLEDGMENT}

This work was sponsored by NASA's Airspace Operations and Safety Program, Safe Autonomous Systems Operations project, led by Parimal Kopardekar, Project Manager. This work was conducted as part of an Interagency Agreement, No. IA1-20800, between the National Aeronautics and Space Administration (NASA), Langley Research Center, and the U.S. Department Of Transportation, FAA. This work could not have been possible without the hard work, diligence, assistance and support of Mr. Harry Hodges (AFS-440), Mr. Doug Rodzon, and the entire AFS-440 Flight Simulation Branch who were instrumental to this research. The support of Mr. Bruce DeCleene (AFS-400) was also critical and is gratefully acknowledged. The technical assistance of Dr. Robert "Buck" Joslin - the FAA Chief Scientist and Technical Advisor for Flight Deck Technology Integration - was critical to the simulation planning. Further, the help of Mr. Bryan Burks, Alaska Airlines, was instrumental in the development of our test scenarios.

\section{REFERENCES}

[1] Li, G., Baker, S.P., Grabowski, J.G., and Rebok, G.W., "Factors Associated with Pilot Error in Aviation Crashes," Aviation, Space, and Environmental Medicine, Vol. 72, No. 1, January 2001.

[2] Air Line Pilots Association, "Air Line Pilots Association White Paper on Unmanned Aircraft Systems," April 2011.

[3] Federal Aviation Administration Advisory Circular: Aviation Safety Action Program, AC-120-66B, Dated November, 2002.

[4] Emergency and Abnormal Situations in Aviation Symposium, LOSA Data and Emergency and Abnormal Situations http://human-factors.arc.nasa.gov/flightcognition/download/EAS_Symposium_Presentati ons/LOSA.pdf, June 10-11, 2003.

[5] Etherington, T.J., Kramer, L.J., Kennedy, K.D., Bailey, R.E., and Stephens, C.L., "Quantifying Pilot Contribution to Flight Safety for Normal and Non-Normal Airline Operations", Paper presented at AIAA Digital Avionics Systems Conference, October 2016.

[6] Hart, S.G. \& Staveland, L.E., "Development of NASA-TLX (Task Load Index): Results of Empirical and Theoretical Research." In P.A. Hancock \& N. Meshkati (Eds.), Human Mental Workload. Amsterdam: North-Holland, 1988, pp. 139-183. 